\title{
PROGRAM GERAKAN LITERASI MA'ARIF DALAM MENINGKATKAN MODERASI BERAGAMA (WASATIYYAH ISLAM)
}

\section{THE MA'ARIF LITERATION MOVEMENT PROGRAM IN IMPROVING RELIGIOUS MODERATION (WASATIYYAH ISLAM)}

\author{
Hamidulloh Ibda1a Aji Sofanudin ${ }^{2 b}$ \\ 1Institut Islam Nahdlatul Ulama Temanggung \\ 2Balai Penelitian dan Pengembangan Agama Semarang \\ aE-mail: h.ibdaganteng@gmail.com \\ bE-mail:ajisofan@gmail.com
}

\begin{abstract}
ABSTRAK
Tujuan penelitian ini adalah untuk mendeskripsikan moderasi beragama (wasatiyyah Islam) dalam program Gerakan Literasi Ma'arif (GLM) Lembaga Pendidikan Ma'arif NU Jawa Tengah periode 2018-2023. Metode penelitian ini adalah kualitatif deskriptif dengan teknik pengumpulan data observasi, dokumentasi, dan wawancara. Hasil penelitian menunjukkan moderasi beragama melalui program Gerakan Literasi Ma'arif (GLM) sangat efektif dalam membentuk karakter literat dan moderat. Muatan moderasi beragama dalam Gerakan Literasi Ma'arif (GLM) bersumber dari karakter dalam Penguatan Pendidikan Karakter (PPK), prinsip dasar Aswaja Annahdliyah, Ukhuwah Nahdliyah, dan Mabadi Khaira Ummah. Dampak program Gerakan Literasi Ma'arif (GLM) menjadikan guru dan siswa literat dan moderat.
\end{abstract}

Kata Kunci: Moderasi Beragama; GLM, Literasi; Ma'arif; Siswa.

\section{ABSTRACT}

The purpose of this study is to describe religious moderation in Ma'arif Literacy Movement program, Nahdlatul Ulama Central Java in the period 2018-2023. This research method is descriptive qualitative by using the techniques of observation, documentation, and interviews to collect the data. The results show that religious moderation through Ma'arif Literacy Movement program was very effective in forming literate and moderate characters. The religious moderation characted instilled in Ma'arif Literacy Movement comes from Strengthening Character Education, basic principles of Aswaja Annahdliyah, Ukhuwah Nahdliyah, and Mabadi Khaira Ummah. The impact of the program makes teachers and students literate and moderate.

Keywords: Religious Moderation; GLM, Literacy; Ma'arif; Students 


\section{PENDAHULUAN}

Mafhum bahwa gejala radikalisme agama muncul di berbagai daerah, tak terkecuali di Jawa Tengah. Temuan penelitian yang dilakukan Tim Peneliti BLA Semarang menunjukkan masih ditemukan pemahaman dan sikap keagamaan siswa sekolah negeri di Jawa Tengah yang bersifat radikal (Suara Merdeka, 25/8/2017). Beberapa siswa setuju mengubah dasar negara Pancasila dan NKRI. Demikian juga, masih ditemukan kebijakan SMK di Jawa Tengah yang mewajibkan seluruh siswinya mengenakan jilbab (Tribun Jateng, 01/11/2017).

Radikalisme dan terorisme di Jawa Tengah masih memprihatinkan. Badan Kesatuan Bangsa dan Politik (Kesbangpol) Jawa Tengah menyebut wilayah Solo Raya, Sukoharjo, dan Karanganyar menjadi zona merah faham radikal. Dari 10.925 narapidana di wilayah Jawa Tengah, 223 adalah napi teroris. Mereka tersebar di 45 lembaga pemasyarakatan dengan jumlah narapidana teroris terbanyak (Budi, 2020). Pada 2019 guru dan siswa SMK Negeri 2 Sragen melakukan pengibaran bendera Hizbut Tahrir Indonesia (HTI) (Marzuki, 2019). Di tahun yang sama, Pemerintah Provinsi Jawa Tengah mengungkap ada tujuh kepala sekolah terpapar radikalisme (Farasonalia, 2019).

Jawa Tengah juga diindikasi dijadikan tempat latihan terorisme. Pada akhir 2020 ditemukan Vila di Gintungan, Bandungan, Kabupaten Semarang digrebek Densus 88 Anti Teror Polri karena tempat itu dijadikan latihan jaringan teroris muda jaringan Jamaah Islamiyah. Mereka dilatih secara militer dengan tujuan membentuk pasukan jihad Jamaah
Islamiyah (Sailendra, 2020). Data ini membuktikan terorisme harus menjadi prioritas utama untuk diselesaikan.

Perkembangan radikalisme di era Revolusi Industri 4.0 dan Society 5.0 begitu cepat. Pergeseran era manual menuju digital mengubah pola perilaku dan ideologi. Masyarakat yang literat akan mudah menyeleksi berita, informasi, data, gambar, maupun video. Namun sebaliknya, bagi mereka yang tidak literat akan mudah tergiring opini, isu, bahkan menjadi korban hoaks, intoleransi, dan radikalisme.

Intensitas manusia dengan peranti teknologi melahirkan disrupsi di berbagai bidang, termasuk bidang pendidikan dan keagamaan. Era Revolusi Industri 4.0 dan Society 5.0 ditandai menjamurnya rekayasa teknologi, kecerdasan buatan, mendekatkan manusia dengan mesin dan internet. Dua hal ini menjadi kebutuhan dasar yang berpotensi melemahkan nasionalisme (Widodo, Karnawati, 2019). Ketika nasionalisme sudah lemah maka manusia mudah disusupi faham intoleransi. Ketika intoleran maka menjadi embrio lahirnya radikalisme dan terorisme.

Perubahan zaman memaksa masyarakat memanfaatkan teknologi dan meninggalkan kebergantungan pada alat-alat konvensional. Di dalam pendidikan peran guru sebagai aktor perubahan sangat penting untuk menjadikan siswa melek literasi. Pasalnya, pengaruh aktor perubahan sangat dominan dalam mengubah pola hidup mereka (Nugraha, 2013). Dalam konteks pendidikan, peran pendidik sangat dominan untuk mendesain siswa melek literasi dan memiliki karakter moderat. 
Ironisnya kaum radikal memanfaatkan media baru untuk menyebar radikalisme. Sasaran mereka tidak sekadar masyarakat umum melainkan masuk ke ruang-ruang pendidikan yang di dalamnya ada pendidik, tenaga kependidikan dan siswa. Masuknya radikalisme di kalangan pelajar perlu perhatian serius. Pasalnya, radikalisme mulai menyusup dan berkembang di dalam lembaga pendidikan formal (Nugraha, Fauzan, 2020). Salah satunya masuk melalui jaringan mentoring rohis yang ada di sekolah (Sofanudin, 2017).

LaKIP Jakarta pada 2010-2011 menemukan 49 siswa di Jabodetabek setuju dengan aksi radikalisme demi agama. Penelitian BIN pada 2017 menemukan 24 persen mahasiswa, 23,3 persen pelajar SMA setuju dengan tegaknya negara Islam. Sebuah yayasan pendidikan di Kabupaten Semarang pada 2016 memecat 13 guru karena mengajarkan faham radikal (Ma'arif, 2020). Belakangan insiden pengeboman ramai di media massa. Terbaru kasus teror bom di Markas Besar Kepolisian Republik Indonesia (Mabes Polri), dan sebelumnya teror bom di Gereja Katedral Makassar. Aksi teror di Mabes Polri membuktikan radikalisme sudah menyebar di kalangan pemuda (Ardyansah, 2021).

Salah satu solusi memutus mata rantai radikalisme dan terorisme adalah penguatan moderasi beragama atau moderasi beragama. Akar moderasi beragama adalah tipe beragama yang wasatiyah (tengahtengah). Moderasi beragama merupakan metode beragama jalan tengah atau dengan jalan yang baik (Tim Penyusun Kementerian Agama RI, 2018). Moderasi beragama berarti beragama, berislam jalan tengah dan dengan jalan baik. Dalam pelaksanaannya, moderasi beragama mengutakan nilai tasamuh (toleran), tawazun (seimbang), i'tidal (adil), dan tawassut (pertengahan). Substansi Islam mengajarkan kedamaian, kerukunan, dan keharmonisan (Muhtarom, 2018).

Semua agama hakikatnya mendamaikan, apalagi agama Islam. Maka semua agama hakikatnya mengutamakan moderasi beragama. Secara bahasa, Islam dari kata salam yang berarti pasrah, damai, selamat. Kata Islam berasal dari kata aslama, yuslimu, islaman, yang bermakna melepaskan diri dari segala penyakit lahir dan batin, kedamaian dan keamanan, ketaatan dan kepatuhan (Saepudin, 2019). Islam merupakan agama rahmatan lilalamin yang mengajarkan urgensi moderasi, dan toleran antarsesama manusia. Tidak ada paksaan dalam beragama, dan setiap manusia berhak memilih agama sesuai keyakinannya masing-masing sesuai UUD 1945 (Feriyanto, 2020).

Namun, problem yang mendera pada agama-agama besar hari ini ditandai dengan merebaknya ekstremisme, radikalisme, intoleransi, dan eksklusivisme (Manshur, Husni, 2020). Semua agama memiliki ajaran moderasi yang menolak faham-faham tersebut. Hadirnya moderasi beragama dalam pendidikan tidak sekadar merespon merebaknya radikalisme, terorisme, atau faham transnasional. Moderasi beragama menjadi substansi Islam sejak dulu karena Islam adalah agama rahmat bagi semua alam. Sudah seharusnya sekolah dan madrasah harus mengarusutamakan moderasi beragama. Semua lembaga pendidikan wajib memegang teguh prinsip 
perdamaian, keamanan, taat, patuh, bukan intoleran dan radikal.

Rendahnya kemampuan literasi pada pelajar dan guru menjadi mudahnya mereka terpapar radikalisme dan tidak moderat. Sebab, dalam penelitian yang ada, literasi dapat menjadikan siswa mampu menggunakan informasi dengan bijak dan meningkatkan karakter melalui pembiasaan budaya baik di sekolah (Muliastrini, Handayani, 2021). Literasi sastra, literasi media, peran tokoh agama juga sangat efektif dalam menangkal bahaya radikalisme dalam pendidikan (Hasanah, 2017). Literasi media dapat menjadikan siswa membunuh isu-isu radikalisme, karena mereka akan bijak dan selektif memilih sumber informasi (Hidayat, Lubis, 2021).

Teori Religious-Social Shaping of Technology menegaskan era digital memiliki dampak pada cara beragama manusia. Seperti pudarnya afiliasi pada lembaga keagamaan, pergeseran otoritas keagamaan, individualisme menguat, dan perubahan pluralisme menjadi tribalisme (Campbell, 2010). Teori berikutnya adalah literasi media sebagai wahana kontra narasi radikalisme dapat dilakukan melalui tiga hal. Pertama, penguatan jurnalisme damai. Kedua, peliputan integratif, tuntas, dan ramah terhadap kasus, terdakwa, dan narapidana terorisme. Ketiga, penulisan artikel populer atau opini media massa yang ramah, damai, dan toleran (Idris, 2017).

Karakter toleran dapat dikuatkan melalui literasi. Selain peningkatan keterampilan menulis dan membaca, penelitian ini menemukan literasi dapat meningkatkan karakter moderat pada siswa (Joyo, 2018).
Penelitian lain yang memanfaatkan media siber sangat berdampak pada moderasi beragama. Media NW online sangat efektif dan konstruktif dalam memberikan pemahaman moderasi beragama kepada santri dan warganet muslim melalui konten media (Fahrurrozi, 2019).

Penelitian di atas menunjukkan pemanfaatan literasi media digital sangat berdampak pada moderasi beragama dalam pendidikan. Apalagi di era digital rentan terjadi disrupsi karena dampak kemajuan teknologi informasi, otomasi, komputasi, dan robotisasi. Kondisi ini melahirkan perubahan radikal dan mengakibatkan pola perilaku beragama masyarakat (Faisal, 2020). Apalagi dewasa ini internet berpengaruh besar pada pemuda dalam menumbuhkan rasisme melalui akses ke media digital (Burhani, Waseso, Atieqoh, Hamidi, 2020). Kita tentu masih ingat framing Aksi Bela Islam 212 di Jakarta yang gencar di media sosial. Dari framing dan aktivitas di media sosial ini menimbulkan ekpresi kebencian sampai pada tindak kekerasan (Syahputra, 2020). Maka dibutuhkan gerajan literasi yang mengarah kepada literasi media digital agar masyarakat khususnya pelajar tidak rentan terkena radikalisme karena efek perubahan pola beragama tersebut.

Di tengah gempuran ideologi radikal, ditambah rendahnya kemampuan literasi pada anak bangsa, pemerintah maupun lembaga swasta telah melakukan beberapa gerakan literasi. Seperti contoh Gerakan Literasi Nasional (GLN) yang ranahnya ada Gerakan Literasi Sekolah, Gerakan Literasi Keluarga, dan Gerakan Literasi Masyarakat yang diinisasi Kementerian 
Pendidikan dan Kebudayaan. GLN ini mengarah kepada tujuan revolusi karakter bangsa, menguatkan kebinekaan dan restorasi sosial Indonesia. Pengembangan, penguatan karakter kebangsaan serta penguatan literasi menjadi salah satu unsur penting dalam kemajuan negara dalam menjalani kehidupan di era digital. Forum Ekonomi Dunia (WEF) 2015 menyebut rumus kemajuan suatu bangsa ada tiga, yaitu literasi dasar, kompetensi, dan karakter (Atmazaki, Ali, Muldian, Miftahussururi, Hanifah, Nento, Akbari, 2017). Maka menguatkan karakter dan literasi menjadi keharusan karena sudah sepaket.

\section{Apalagi kebijakan Mendik-} budristek, Nadiem Anwar Makarim yang menjadikan literasi, numerasi, dan survei karakter menjadi hal yang utama dalam sistem evaluasi pendidikan. Ketiga hal tersebut menjadi fokus penyederhanaan kurikulum yang dilakukan oleh Kemendikbudristek. Secara mudah, literasi terkait dengan kemampuan analisis kualitatif. Sementara numerasi merupakan analisis dengan menggunakan angka-angka atau kuantitatif. Pengetahuan kuantitatif dan kualitatif penting sebagai bekal pengembangan semua disiplin ilmu. Sementara karakter menjadi pengikat agar peserta didik menjadi pribadi yang baik (Sofanudin, 2020). Salah satu karakter yang penting adalah menjadikan siswa memiliki karakter yang moderat. Sementara karakter menjadi pengikat agar peserta didik menjadi pribadi yang baik, khususnya karakter beragama yang moderat, wasatiyyah atau moderasi beragama.
GLN yang digelorakan pemerintah sejak 2015 tidak hanya berorientasi pada kemampuan membaca, menulis, dan berhitung. Namun berdasarkan Permendikbud Nomor 23 Tahun 2015 tentang Penumbuhan Budi Pekerti, gerakan tersebut diprioritaskan dalam rangka penguatan karakter dan menumbuhkan spirit kebudayaan, kewargaan atau nasionalisme. Tujuan Gerakan Literasi Sekolah juga untuk menumbuhkembangkan budi pekerti siswa lewat pembudayaan ekosistem literasi sekolah agar mereka menjadi pembelajar sepanjang hayat (Kemdikbud, 2016).

Salah satu lembaga pendidikan yang melakukan inovasi atas program GLN itu adalah Lembaga Pendidikan Ma'arif PWNU Jawa Tengah yang mendesain program Gerakan Literasi Ma'arif (GLM). Tujuan GLM ini tidak sekadar meningkatkan kemampuan literasi, namun juga penguatan moderasi beragama. Lewat LP Ma'arif, NU sejak lama dikenal sebagai organisasi yang teologinya sangat moderat dan pluralis (Arifianto, 2017).

Dari latar belakang tersebut, peneliti tertarik meneliti moderasi beragama melalui program GLM yang dilakukan Lembaga Pendidikan Ma'arif PWNU Jawa Tengah. Secara operasional, penelitian ini untuk mengetahui bagaimana (1) Gerakan Literasi Ma'arif, (2) Muatan Moderasi Beragama dalam Gerakan Literasi Ma'arif, (3) Tantangan dan Peluang Pelaksanaan Gerakan Literasi Ma'arif. Dari latar belakang, kajian teori, dan kajian penelitian di atas, perbedaan dengan riset yang akan penulis lakukan lebih pada objek, sasaran, dan bentuk programnya. GLM fokus di 
Jawa Tengah, hanya pada sekolah/madrasah di bawah Lembaga Pendidikan Ma'arif PWNU Jawa Tengah.

GLM dalam penelitian ini fokusnya tidak hanya pada karya literasi, namun lebih pada pengarusutamaan moderasi beragama dalam kegiatan literasi yang diproyeksikan selama lima tahun dari 2018 sampai 2023. Sampai Mei 2021, belum ada laporan radikalisme di sekolah/madrasah naungan Lembaga Pendidikan Ma'arif di Jateng. Namun berdasarkan amanat PBNU dan PP LP Ma'arif NU, LP Ma'arif PWNU Jateng sebagai lembaga yang menaungi sekolah/madrasah memiliki misi menguatkan moderasi beragama melalui program GLM sebagai langkah preventif mencegah radikalisme.

\section{METODE}

Metode kualitatif dipilih dalam melakukan penelitian ini. Motode penelitian kualitatif bertujuan mengeksplorasi dan memahami makna dari masalah sosial khususnya dalam pendidikan di Lembaga Pendidikan Ma'arif PWNU Jawa Tengah. Instrumen pengumpul data melalui observasi, dokumentasi, dan wawancara dari pengurus Lembaga Pendidikan Ma'arif NU Jawa Tengah periode 2018-2023, tim, fasilitator, relewan, mitra, dan pelaku GLM.

Sumber data primer dalam penelitian ini berupa data dari informan berdasarkan observasi, dokumentasi, dan wawancara dari pengurus Lembaga Pendidikan Ma'arif NU Jawa Tengah, tim, fasilitator, relewan, mitra, dan pelaku GLM. Data sekunder berupa data sekolah/madrasah di bawah Lembaga
Pendidikan Ma'arif NU Jawa Tengah, buku Modul dan Panduan Teknis GLM, buku terbitan CV. Asna Pustaka, Jurnal ASNA, dokumen di website Maarifnujateng.or.id, video di channel Youtube Ma'arif NU Jateng, catatancatatan terkait kegiatan literasi yang dilakukan Lembaga Pendidikan Ma'arif NU Jawa Tengah.

Subjek penelitian ini Lembaga Pendidikan Ma'arif NU Jawa Tengah yang menaungi 3.335 satuan pendidikan. Rinciannya yaitu 1697 Madrasah Ibtidaiyah, 23 Sekolah Dasar, 552 Madrasah Tsanawiyah, 116 Sekolah Menengah Pertama, 197 Madrasah Aliyah, 41 Sekolah Menengah Atas, 159 Sekolah Menengah Kejuruan, dan 1 Sekolah Luar Biasa. Sedangkan jumlah sasarannya, yaitu tenaga pendidik dan siswa dengan rincian 34.389 tenaga pendidik dan 352740 siswa. Pengumpulan data dilakukan selama satu bulan sejak 1 Mei 2021 sampai 30 Mei 2021. Dalam penelitian ini peneliti mendeskripsikan dan menganalisis program GLM Lembaga Pendidikan Ma'arif NU Jawa Tengah periode 20182023, muatan moderasi beragama dalam GLM, serta tantangan dan peluang pelaksanaan GLM.

\section{HASIL DAN PEMBAHASAN \\ Program Gerakan Literasi Ma'arif}

GLM merupakan program prioritas Lembaga Pendidikan Ma'arif NU Jawa Tengah selain pendidikan inklusi, penguatan karakter moderat melalui kurikulum Aswaja Annahdliyah. Ma'arif merupakan lembaga di bawah PWNU Jawa Tengah yang bertugas mengurusi pendidikan madrasah dan sekolah, dari jenjang SD/MI sampai SMA/SMK/MA yang pada periode 2018-2023 ini fokus 
menguatkan moderasi beragama, gerakan literasi, dan pendidikan inklusi. Tahapan GLM dimulai tahun 2018 dengan penyusunan program oleh tim pengembang dari unsur widyaiswara, dosen, guru, kepala sekolah, pengawas, jurnalis, youtuber, blogger, dan juga aktivis literasi. Tahun 2019 penyusunan modul dan implementasi sampai evaluasi pada tahun 2023.

GLM merupakan sebuah usaha atau gerakan secara sadar yang terstruktur, terencana, sistematis untuk meningkatkan kualitas literasi di dalam kegiatan pembelajaran dan di luar pembelajaran. GLM dalam pelaksanaannya dikuatkan melalui muatan karakter dari Penguatan Pendidikan Karakter (PPK) dan Aswaja Annahdliyah yang di dalamnya ada spirit moderasi beragama (Irawan, Ibda, Niam, Munif, 2019). Pelaksanaan GLM dipraktikkan dengan dua metode, yaitu praktik mandiri dan praktik sinergi dengan pola "pembelajaran, pembiasaan, keteladanan" dan tiga pilar yaitu "baca, tulis, arsip". GLM dapat dikembangkan sekolah/madrasah sesuai pengetahuan lokal, jenius lokal, kearifan lokal, sarana dan prasarana yang ada.

GLM mengacu pada paradigma literasi literasi lama (membaca, menulis, berhitung) dan keterampilan literasi baru (literasi data, literasi teknologi, literasi manusia/SDM). Jenis karya dalam GLM ada empat, yaitu karya tulis jurnalistik, karya tulis ilmiah, karya sastra, dan karya digital.

$$
\text { Tujuan GLM dalam }
$$

pembelajaran untuk menguatkan dan mendukung ketercapaian standar kompetensi lulusan pembelajaran dalam kompetensi inti/kompetensi dasar sesuai mata pelajaran masingmasing. Tujuan umum GLM untuk menguatkan karakter literat dengan paradigma literasi dan literasi baru melalui pembiasaan, pembelajaran, dan keteladanan agar guru dan siswa menjadi generasi nasionalis, religus, mandiri, gotong royong, dan terintegrasi dengan nilai-nilai Aswaja Annahliyah. Sementara tujuan khusus GLM yaitu (1) penguatan ideologi dan karakter Aswaja Annahdliyah lewat literasi, (2) pembudayaan tradisi-tradisi Islam Nusantara lewat kegiatan literasi, (3) penguatan budaya literasi lama dan literasi baru, menumbuhkembangkan keterampilan literasi pelajar agar terhindar dari hoaks dan radikalisme, dan (5) menumbuhkembangkan budaya tabayun (klarifikasi) pada pelajar dalam ekosistem sekolah dan madrasah Ma'arif.

Bentuk kegiatan GLM melalui pembelajaran, pembiasaan, pendidikan dan pelatihan, penerbitan dan percetakan, perlombaan, dan temu penulis-sastrawan. Implementasi program ini dilakukan dengan dua model, yaitu praktik mandiri dan praktik sinergi yang dilakukan melalui pembelajaran intrakurikuler dan ekstrakurikuler di sekolah/madrasah.

Bentuk praktik mandiri GLM meliputi (1) pembiasaan tradisi literasi Aswaja Annahdliyah, (2) pembentukan Lembaga Pers Siswa (LPS), pelatihan karya tulis jurnalistik, (4) pelatihan karya tulis ilmiah, pelatihan karya sastra, (6) pelatihan karya digital, (7) penerbitan majalah dinding, buletin, majalah, dan tabloid, (8) website sebagai media menulis siswa dan guru, (9) perlombaan, (10) 
ta'ziran atau hukuman menulis, dan (11) penguatan perpustakaan. Sementara implementasi GLM dengan model sinergi yaitu (1) pelatihan karya tulis jurnalistik, (2) pelatihan karya tulis ilmiah, (3) pelatihan karya sastra, (4) pelatihan karya digital, (5) pelatihan media siber Aswaja Annahdliyah dan (6) pelatihan penulisan bahan ajar.

Penerbitan dan percetakan GLM terdiri atas beberapa aspek, yaitu Majalah MOPDIK, Jurnal ASNA, Penerbit dan Percetakan CV. Asna Pustaka, website Maarifnujateng.or.id, Facebook Ma'arif NU Jateng, Instagram Ma'arif NU Jateng, dan Youtube Ma'arif NU Jateng. Berdasarkan data yang didapat, masing-masing penerbitan-percetakan, publikasidokumentasi melalui media-media produk GLM pada karya tulis jurnalistik, karya tulis ilmiah, karya sastra, dan karya digital dapat dilihat pada tabel di bawah ini:

Tabel 1: Jumlah karya produk GLM dari 2018-2021

\begin{tabular}{|c|c|c|c|c|}
\hline No & Produk & $\begin{array}{l}\text { Jenis } \\
\text { Karya }\end{array}$ & $\begin{array}{l}\text { Frekuensi } \\
\text { Terbit }\end{array}$ & Jumlah \\
\hline 1 & $\begin{array}{l}\text { Majalah } \\
\text { Mopdik }\end{array}$ & $\begin{array}{l}\text { Jurnalist } \\
\text { ik, } \\
\text { Sastra }\end{array}$ & $\begin{array}{l}1 \text { tahun } 1 \\
\text { kali }(2019- \\
2020)\end{array}$ & 40 \\
\hline 2 & $\begin{array}{l}\text { Jurnal } \\
\text { ASNA }\end{array}$ & Ilmiah & $\begin{array}{l}6 \text { Bulan 1 } \\
\text { kali } \quad(2019- \\
2020)\end{array}$ & 34 \\
\hline 3 & $\begin{array}{l}\text { CV. } \\
\text { ASNA } \\
\text { Pustaka }\end{array}$ & $\begin{array}{l}\text { Ilmiah } \\
\text { dan } \\
\text { sastra }\end{array}$ & 2019-2021 & 48 \\
\hline \multirow[t]{5}{*}{4} & $\begin{array}{l}\text { Maarifnujat } \\
\text { eng.or.id }\end{array}$ & Berita & $\begin{array}{l}\text { November } \\
2018-M e i \\
2021\end{array}$ & 691 \\
\hline & & $\begin{array}{l}\text { Artikel/ } \\
\text { esai }\end{array}$ & $\begin{array}{l}\text { Agustus 2019- } \\
\text { Mei } 2021\end{array}$ & 464 \\
\hline & & Resensi & $\begin{array}{l}\text { Agustus 2019- } \\
\text { Mei } 2021\end{array}$ & 116 \\
\hline & & Cerpen & $\begin{array}{l}\text { Agustus 2019- } \\
\text { Mei } 2021\end{array}$ & 116 \\
\hline & & Puisi & $\begin{array}{l}\text { Agustus 2019- } \\
\text { Mei } 2021\end{array}$ & 116 \\
\hline 5 & $\begin{array}{l}\text { Youtube } \\
\text { Maarif } \\
\text { NU } \\
\text { Jateng }\end{array}$ & Video & $\begin{array}{cc}5 & \text { Februari } \\
2019 & -30 \text { Mei } \\
2021 & \end{array}$ & 346 \\
\hline 6 & & & Jumlah & 1971 \\
\hline
\end{tabular}

Selain karya-karya di atas, tim GLM juga melakukan pendidikanpelatihan dan perlombaan yang berorientasi pada produk dari peserta. Jumlahnya dapat dilihat pada tabel di bawah ini:

Tabel 2: Jumlah karya produk pendidikan, pelatihan, dan perlombaan GLM dari 2019-2021

\begin{tabular}{|c|c|c|}
\hline No & $\begin{array}{l}\text { Pelatihan/ } \\
\text { Perlombaan }\end{array}$ & $\begin{array}{l}\text { Pelaksana Jumlah } \\
\text { an }\end{array}$ \\
\hline \multirow[t]{3}{*}{1} & $\begin{array}{ll}\text { Diklat GLM } & \text { Artikel-esai } \\
1 & \text { populer }\end{array}$ & $\begin{array}{l}27-28 \\
\text { Desember } \\
2019\end{array}$ \\
\hline & Puisi & $\begin{array}{l}27-28 \\
\text { Desember } \\
2019\end{array}$ \\
\hline & Cerpen & $\begin{array}{l}27-28 \\
\text { Desember } \\
2019\end{array}$ \\
\hline 2 & $\begin{array}{l}\text { Lomba } \\
\text { Karya Tulis } \\
\text { Ilmiah }\end{array}$ & $\begin{array}{l}12 \\
\text { Desember } \\
2019\end{array}$ \\
\hline 3 & $\begin{array}{lll}\text { Lomba } & \text { Desain } & \text { Desain } \\
\text { Batik } & & \text { Batik } \\
\end{array}$ & 18 Februari 2020 \\
\hline 4 & $\begin{array}{ll}\text { Lomba Cipta } & \text { Video } \\
\text { Video Profil } & \text { Profil }\end{array}$ & $\begin{array}{l}15 \text { Februari } \\
\text { 2020- } \\
\text { 1 Desember } 2020\end{array}$ \\
\hline 5 & $\begin{array}{lll}\text { Kuliah Literasi dan } & \text { Berita } \\
\text { Jurnalistik (Diklat } & \\
\text { GLM ke-2) } & & \\
\end{array}$ & 15 Juni 2020 \\
\hline 6 & $\begin{array}{lll}\begin{array}{l}\text { Kuliah } \\
(\text { GLM ke-3) }\end{array} & \text { Sastra } & \begin{array}{l}\text { Puisi dan } \\
\text { Cerpen }\end{array} \\
\end{array}$ & 22 Juni 2020 \\
\hline 7 & $\begin{array}{lll}\text { Kuliah } & \text { Artikel } & \text { Artikel- } \\
\text { Populer } & \text { (Diklat } & \text { esai } \\
\text { GLM ke-5) } & \text { populer }\end{array}$ & 6 Juli 2020 \\
\hline 8 & $\begin{array}{l}\text { Kuliah Resensi Resensi } \\
(\text { GLM ke-6) }\end{array}$ & 13 Juli 2020 \\
\hline 9 & $\begin{array}{l}\text { Kuliah } \\
\text { Literasi dan } \\
\text { Jurnalistik } \\
\text { (Diklat GLM } \\
\text { ke-11) }\end{array}$ & $\begin{array}{l}6 \\
\text { November } \\
2020\end{array}$ \\
\hline & & Jumlah \\
\hline
\end{tabular}

Selain karya-karya yang diarsipkan melalui media penerbitan dan percetakan milik tim GLM, para peserta pendidikan-pelatihan juga mampu melakukan publikasi di media cetak maupun elektronik yang lain. Seperti Duta Masyarakat, Tribun Jateng, Harian Bhirawa, Harian Matabanua, Tabayuna.com, Harianjateng.com, Hariansemarang.com, Harianblora.com, 
Harianguru.com, Hariantemanggung.com, Babe.news, Kabartemanggung.com, Ayosemarang.com, Galamedianews.com, Suaranahdliyin.com, Patinews.com, G-News.id, Nu.or.id, dan lainnya.

\section{Moderasi Beragama Dalam Gerakan Literasi Ma'arif}

Moderasi beragama dalam GLM ini tercantum dalam beberapa program yang dikuatkan melalui muatan karakter yang terdiri atas nilai-nilai karakter sesuai Peraturan Menteri Pendidikan dan Kebudayaan Nomor 23 Tahun 2015, Perpres 87 Tahun 2017 tentang Penguatan Pendidikan Karakter (PPK) dan Permendikbud Nomor 20 Tahun 2018 tentang Penguatan Pendidikan Karakter (PPK) Pada Satuan Pendidikan Formal, dan karakter Aswaja Annahdliyah. Karakter utama dalam Penguatan Pendidikan Karakter (PPK) meliputi religius, nasionalis, gotong royong, integritas, mandiri. Kelima karakter ini kemudian dispesifikkan menjadi 17 karakter ke dalam kegiatan teknis GLM. Mulai dari karakter religius, jujur, toleran, disiplin, bekerja keras, kreatif mandiri, demokratis, rasa ingin tahu, semangat kebangsaan, cinta tanah air, menghargai prestasi, komunikatif, cinta damai, gemar membaca, peduli lingkungan, peduli sosial, dan tanggungjawab.

Sedangkan karakter moderasi beragama mengacu kepada nilai-nilai Aswaja Annahdliyah yang kiblatnya dari beberapa prinsip. Pertama, prinsip dasar Aswaja Annahdliyah terdiri atas at-tawassuth (sikap tengahtengah/moderat), at-tawazun (seimbang), at-tasamuh (toleransi), $i^{\prime}$ tidal (tegak lurus), amar ma'ruf nahi munkar (menjaga kepada yang baik, dan mencegah keburukan), dan maslahah mursalah

(mengambul hukum/kebijakan sesuai kepentingan publik). Kedua, karakter Ukhuwah Nahdliyah yang terdiri atas ukhuwah islamiyah (persaudaraan umat Islam), ukhuwah wathaniyah (persaudaraan kebangsaan), dan ukhuwah basyariyah/ukhuwah insaniyah (persaudaraan umat manusia). Ketiga, nilai-nilai dalam Mabadi Khaira Ummah (umat terbaik) yang tercantum dalam mabadi khamsah yaitu ash-shidqu (kejujuran/kebenaran), al-amalah wal wafa bil'ahdi (mampu melaksanakan tugas sesuai janji), al'adalah (objektif, adil), at-ta'awun (suka menolong), istiqamah (konsisten).

Moderasi beragama yang dimaksud di sini merupakan usaha untuk menempatkan agama (Islam) sebagai agama yang seimbang, tengahtengah, tidak ekstrim kanan dan kiri dalam dunia pendidikan. Moderasi beragama di sini tercermin dari aspek pikiran (fikrah), keyakinan (aqidah), gerakan (harakah), dan praktik ibadah (amaliyah) yang dikonsep melalui karakter Aswaja Annahdliyah dalam praktik GLM dalam rangka mencegah radikalisme agama.

Moderasi beragama perspektif GLM yang mengacu pada spirit Nahdlatul Ulama ini memiliki karakteristik dan berbeda dengan moderasi barat. Bangunan moderasi beragama perspektif barat dan arus utama moderasinya menggiring pada sekularisasi dan liberalisasi Islam, serta kontradiksi dengan spirit Islam (Amin, 2014:24). Moderasi beragama perspektif Nahdlatul Ulama dalam program GLM ini mengarusutamakan karakter nasionalisme dan religiusitas. Nilai- 
nilai itu sama seperti nilai-nilai moderasi beragama, di antaranya attawashut (moderat), at-tawazun (sikap seimbang), at-tasamuh (toleransi), atta'adul (tegak lurus), amar ma'ruf nahi munkar (menyeru perbuatan baik dan melarang kejahatan) (Widayat, et.al, 2019).

Moderasi beragama dalam GLM ini tersalurkan melalui beberapa aspek. Pertama, melalui ribuan karya yang sudah diproduksi tersebut. Mulai dari karya tulis jurnalistik, karya tulis ilmiah, karya sastra, dan karya digital. Kedua, melalui penggiringan isu, pemberitaan, dan warta narasi moderasi beragama di website Maarifnujateng.or.id melalui tulisan bergenre berita, artikel-esai populer, artikel hikmah, resensi, cerita pendek, dan puisi.

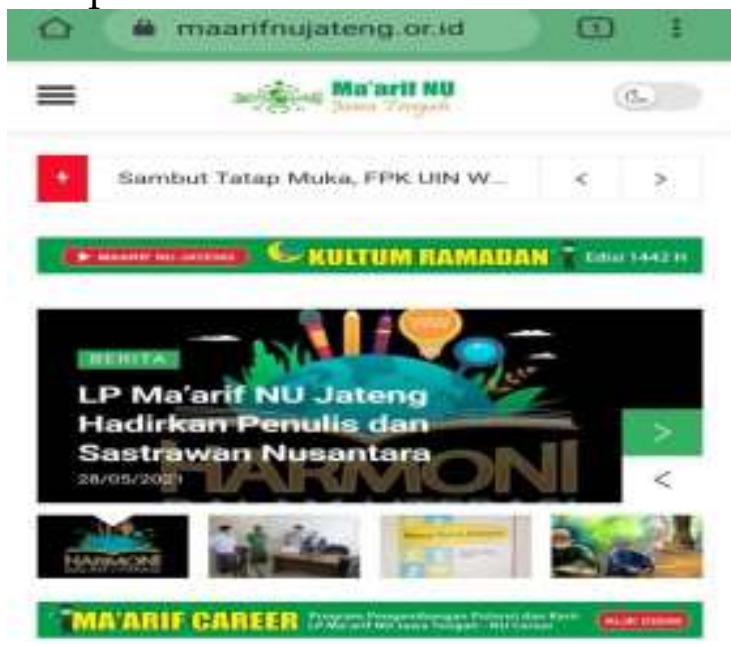

Gambar 1: Tampilan Website

Maarifnujateng.or.id. (dokumentasi peneliti/https://maarifnujateng.or.id).

Ketiga, melalui youtube Ma'arif NU Jateng yang berisi konten live streaming, Kultum Ramadan, Ngaji Kitab Aqidatul Awam, Ruang Gus Dur, Film Pendek Sekolah dan Madrasah, Materi Ke-NU-an, program pendidikan inklusif, video profil madrasah sekolah, ceriga bergambar, review buku, bincang Ma'arif, serba-serbi, irama Ma'arif, ngaji bareng Ma'arif, Liputan Kegiatan Ma'arif, Literasi Ma'arif, dan seni budaya.

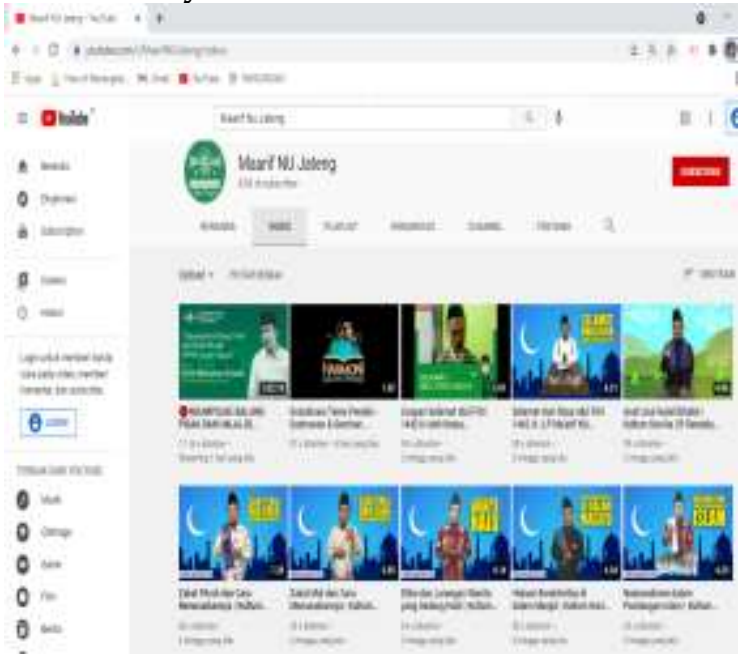

Gambar 2: Tampilan channel Youtube

Maarif NU Jateng. (dokumentasi peneliti/https://www.youtube.com/c

/MaarifNUJateng/featured).

Keempat, melalui media sosial Facebook Ma'arif NU Jateng dan Instagram Maarif NU Jateng. Isinya adalah berita, quote moderat, dan informasi kegiatan yang bernuansa edukatif dan moderasi beragama.

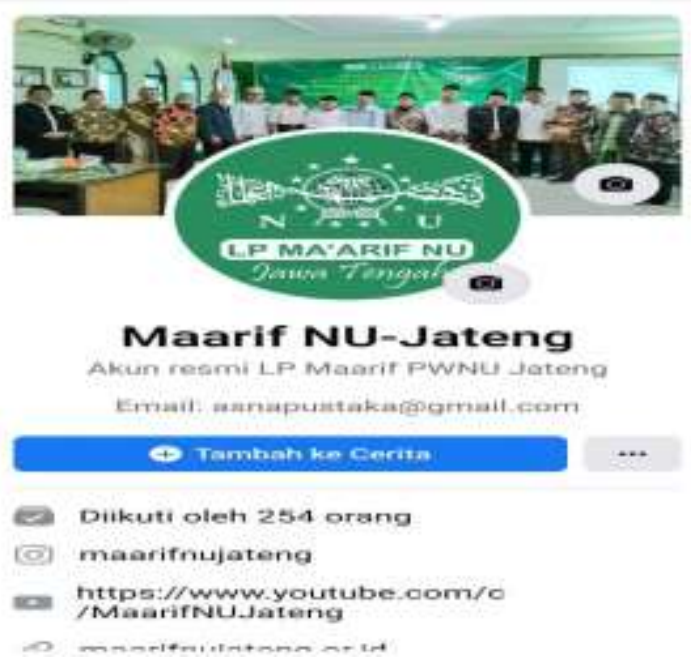

Gambar 3: Tampilan Facebook Ma'arif NU Jateng (dokumen

peneliti/https://www.facebook.com/maja lah.maarif.1). 


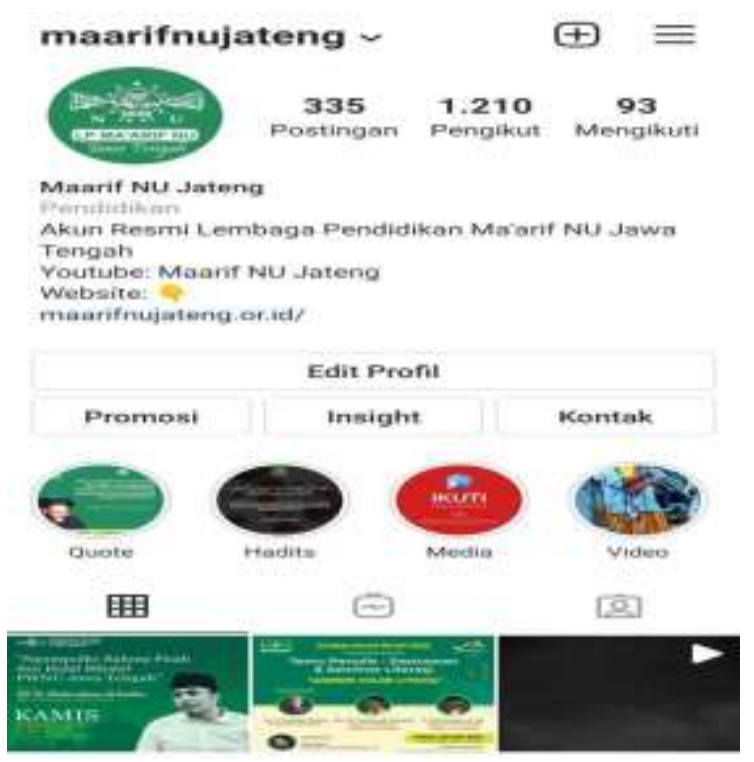

Gambar 4: Tempilan Instagram Maarif

NU Jateng (Sumber: Dokumen

Penulis/https:/ / www.instagram.com/ maarifnujateng/)

Keempat, melalui penerbit dan percetakan buku CV. ASNA Pustaka yang menerbitkan buku-buku pelajaran Ke-NU-an, buku bernuansa Islam ramah, dan buku lain yang moderat.

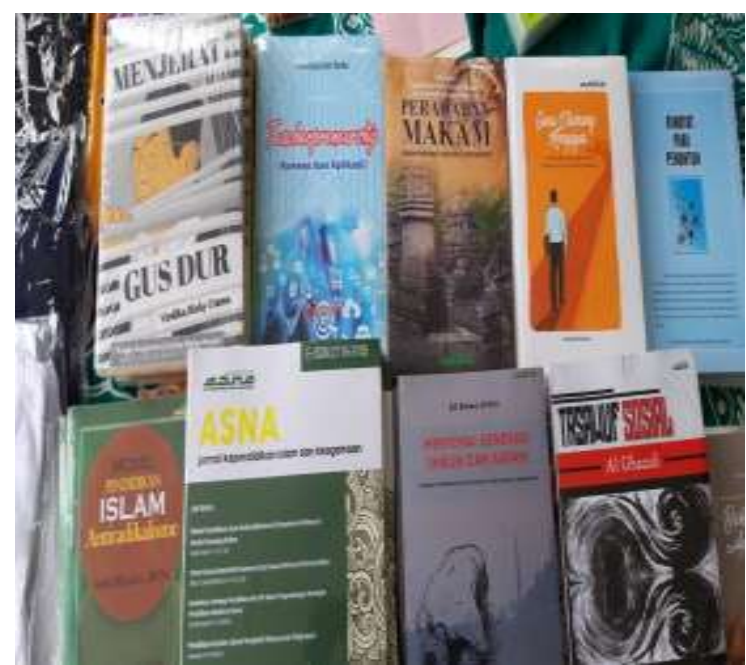

Gambar 5: Beberapa buku terbitan CV. ASNA Pustaka saat dijual di bazar buku (Sumber: Dokumen Peneliti).
Kelima, melalui Majalah Mopdik yang fokus pada edukasi moderasi beragama kepada siswa-siswi. Kelima, melalui Jurnal ASNA yang memuat artikel berkaitan dengan isu-isu keagamaan, dan kependidikan Islam.

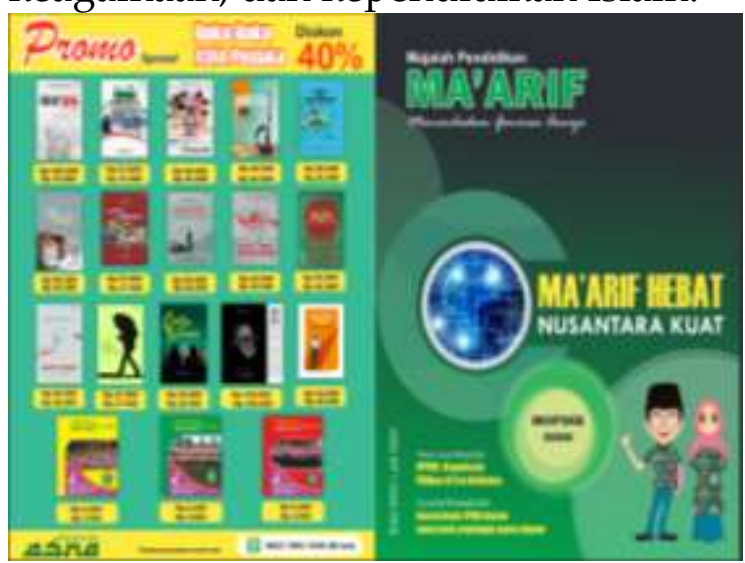

Gambar 6: Majalah Mopdik (Sumber: Dokumen Peneliti / https://maarifnujateng.or.id/majalahmopdik-2020/).

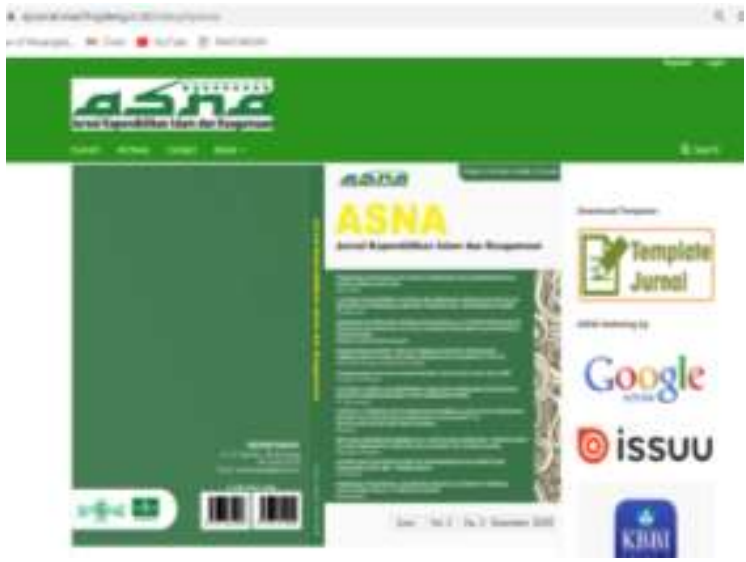

Gambar: 7 tampilan OJS Jurnal ASNA (dok penulis/

https:/ / ejournal.maarifnujateng.or.id/ind ex.php/asna)

Selain melalui kegiatan penguatan literasi yang bermuara pada moderasi beragama, GLM juga menggelar kegiatan khusus dalam penguatan literasi media digital untuk penanaman moderasi beragama. Kegiatan pertama pada 3 Agustus 2020 yaitu pada Diklat GLM ke-9 dengan materi Kuliah Media Aswaja 
Annahdliyah, deteksi media massa moderat dan media radikal, dan karakteristik Aswaja dalam media. Kedua, Diklat GLM ke-10 dengan materi NU dan Politik Media, dan Moderasi beragama lewat media pada 10 Agustus 2020.

Usaha-usaha GLM dari 20182021 sekarang semata-mata tidak hanya mengarah pada penguatan kemampuan literasi, namun juga memprioritaskan moderasi beragama lewat berbagai jenis kegiatan dan beragam karakter-karakter yang diusung melalui paket kegiatan di GLM tersebut.

Dampak dari GLM sangat baik, karena siswa-siswi, guru, kepala sekolah/ madrasah, dan pengurus Lembaga Pendidikan Ma'arif di Cabang, bahkan masyarakat umum termasuk mahasiswa dan dosen terpapar moderasi beragama melalui kegiatan-kegiatan yang dilaksanakan. Selanjutnya, sejak 2018 sampai Mei 2021 belum ada laporan dari 3.335 sekolah/madrasah di Jawa Tengah terindikasi atau berpotensi radikal. Artinya moderasi beragama yang digaungan pengurus Lembaga Pendidikan Ma'arif PWNU Jawa Tengah efektif dalam menanamkan moderasi beragama bagi pelajar, guru, dan masyarakat luas karena disebar melalui media digital.

Usaha-usaha yang dilakukan Lembaga Pendidikan Ma'arif Nahdlatul Ulama Jawa Tengah melalui GLM di atas sudah selaras dengan teori literasi media sebagai metode kontra narasi radikalisme. Pasalnya, dalam GLM sudah menerapkan kegiatan jurnalisme damai, peliputan kegiatan yang integratif, dan penulisan artikel dan esai populer di media website
Maaarifnujateng.or.id, CV. ASNA Pustaka, dan Jurnal ASNA. Selain itu, dalam GLM juga sudah berkonversi ke media baru dengan produkti konten moderat di Youtube dan pembuatan meme.

\section{Tantangan dan Peluang}

Meski GLM dapat dikatakan sukses dalam menanamkan sekaligus menguatkan moderasi beragama melalui kegiatan dan media-media baru atau ber-platform digital, namun program ini dalam perjalanannya mengalami tantangan dan peluang.

Tantangannya pertama masih sedikit sekolah/madrasah yang mampu mempromosikan program ini kepada sekolah/madrasah umum, negeri, atau di luar naungan Lembaga Pendidikan Ma'arif. Kedua, masih minimnya keikutsertaan siswa khususnya jenjang SD/MI sampai SMP/MTs. Ketiga, pola hidup dan guru dan siswa Ma'arif yang bergeser pada jiwa konsumtif pada media sosial. Keempat, pandemi covid-19 yang berkepanjangan menjadikan guru dan pelajar Ma'arif malas dalam melakukan kegiatan literasi. Kelima, minimnya media-media massa lokal, youtuber, blogger yang mendukung implementasi di tingkat kabupaten/ kota. Keenam, banyaknya media baru yang belum dikuasai guru dan pelajar sehingga dalam pelaksanaan pembelajaran moderasi beragama masih terkendala pada media-media yang bagi mereka terstigma susah dan ribet.

Sedangkan peluangnya, pertama respon positif dari pegiat literasi, jurnalis media, sastrawan akan program GLM. Khususnya program penulisan di website Maarifnujateng.or.id yang disediakan 
honor khusus. Kedua, banyaknya jaringan dari unsur pemilik media, penerbit dan percetakan besar ingin membantu dan mengajak wirausaha melalui kegiatan itu dengan tim GLM. Ketiga, adanya potensi kolaborasi dengan lembaga, ormas, dan organisasi profesi keguruan, kemahasiswaan, untuk bermitra dengan tim GLM dalam membuat pendidikan-pelatihan, bazar, maupun perlombaan. Keempat, permintaan buku ajar dan pendampingan sekolah/ madrasah Ma'arif di luar Jawa Tengah, luar Jawa khususnya pada aspek ideologisasi moderasi beragama pada buku-buku Islam, buku pelajaran yang ramah dan toleran. Kelima, banyaknya relawan literasi sebagai kontributor, penulis, penggerak literasi yang secara sadar dan inisiatif mengirim artikel, berita, dan laporan kegiatan bernuansa edukatif, moderasi beragama ke media maupun penerbitan yang dikelola tim GLM.

GLM mirip dengan Gerakan Literasi Madrasah (GELEM) yang dilakukan oleh Kanwil Kementerian Agama Provinsi Jawa Timur. Gelem merupakan usahan komprehensif untuk menjadikan madrasah sebagai masyarakat pembelajar yang dilakukan semua pihak baik pemerintah, guru, peserta didik, maupun orang tua wali. Gelem merupakan bagian dari GERAMM (Gerakan Ayo Membangun Madrasah) yang meliputi: gerakan literasi madrasah (GELEM), gerakan madrasah sehat (GEMES), Gerakan madrasah inovatif (GEMI), Gerakan Furudlul Ainiyah (GEFA), peningkatan kompetensi guru (KATA SIGURU), peningkatan kompetensi kepala madrasah (KATA SIKAMAD), dan peningkatan kompetensi pengawas (KATA SIAWAS) (Kanwil Kemenag Jawa Timur, 2019).

\section{KESIMPULAN}

GLM menjadi jawaban atas ketertinggalan kemampuan literasi dan penguatan moderasi beragama bagi guru, tenaga kependidikan, dan siswa di bawah sekolah/madrasah Lembaga Pendidikan Ma'arif PWNU Jawa Tengah. Selain penguatan kemampuan literasi lama, GLM memiliki muatan moderasi beragama yang mengacu nilai-nilai/karakter religius, jujur, toleran, disiplin, bekerja keras, kreatif mandiri, demokratis, rasa ingin tahu, semangat kebangsaan, cinta tanah air, menghargai prestasi, komunikatif, cinta damai, gemar membaca, peduli lingkungan, peduli sosial, dan tanggungjawab. Selain mengacu nilainilai ini, muatan moderasi beragama pada GLM juga dikuatkan melalui nilai/karakter yang bersumber pada prinsip dasar Aswaja Annahdliyah, karakter Ukhuwah Nahdliyah, dan nilainilai dalam Mabadi Khaira Ummah.

Penelitian ini memberi saran kepada stakeholders GLM untuk kontinu dalam melaksanakan inovasi dalam menguatkan kemampuan literasi dan moderasi beragama meski di tengah pandemi covid-19. Penelitian ini juga memberikan saran kepada peneliti berikutnya untuk dapat mengeksplore lebih dalam tentang gerakan literasi lain yang diinisasi lembaga pendidikan yang mengarusutamakan moderasi beragama. 


\section{DAFTAR PUSTAKA}

Amin, R. (2014). Prinsip dan Fenomena Moderasi Islam dalam Tradisi Hukum Islam. Al-Qalam, 20, 23-32. https://doi.org/http://dx.doi.org/10.31969/alq.v20i3.339

Ardyansah, V. (2021, April). GP Ansor Jateng: Hati-hati Doktrin Radikalisme ke Anak Muda.

Ayosemarang.Com.

https:/ / www.ayosemarang.com/read/2021/04/01/74447/gp-ansor-jatenghati-hati-doktrin-radikalisme-ke-anak-muda.

Arifianto, A. R. (2017). Practicing What it Preaches? Understanding the Contradictions Between Pluralist Theology and Religious Intolerance Within Indonesia's Nahdlatul Ulama. Al-Jami'ah Journal of Islamic Studies, 55, 241-264. https:/ / doi.org/10.14421/ajis.2017.552.241-264.

Atmazaki; Ali, Nur Berlian Venus; Muldian, Wien; Miftahussururi; Hanifah, Nur; Nento, Meyda Noorthertya; Akbari, Qori Syahriana. (2017). Panduan Gerakan Literasi Nasional. Jakarta: Kementerian Pendidikan dan Kebudayaan.

Budi, T. (2020). Solo Raya Masih Zona Merah Radikalisme. Okezone.Com. https:/ / news.okezone.com/read/2020/02/19/512/2171094/solo-raya-masihzona-merah-radikalisme.Burhani, Haris; Waseso, Hendri Purbo; Atieqoh, Siti; Hamidi, A. Luthfi. (2020). Mainstreaming Religious Moderation on Millennial Generation through Religious Literacy on Social Media. Proceedings of the 3rd International Symposium on Religious Life. https:/ / eudl.eu/doi/10.4108/ eai.2-112020.2305069.

Campbell, Heidi A. (2010). When Religion Meets New Media. City, London: Routledge.

Fahrurrozi, M. T. (2019). Media dan Dakwah Moderasi: Melacak Peran Strategis dalam Menyebarkan Faham Moderasi di Situs Nahdlatul Wathan On-Line Situs Kalangan Netizen Muslim-Santri. Tasamuh: Jurnal Komunikasi Dan Pengembangan Masyarakat Islam, 1755-180. https://doi.org/https://doi.org/10.20414/tasamuh.v17i1.1440.

Faisal, M. (2020). Manajemen Pendidikan Moderasi Beragama Di Era Digital. ICRHD: Journal of International Conference On Religion, Humanity and Development, 195202. https://confference.iainptk.ac.id/index.php/icrhd/article/view/17/17.

Farasonalia, R. (2019, September). 7 Kepala Sekolah di Jateng Terpapar Radikalisme, Ganjar Tindak Tegas. Kompas.Com. https:/ / regional.kompas.com/read/2019/09/16/08491381/7-kepala-sekolahdi-jateng-terpapar-radikalisme-ganjar-tindak-tegas?page $=$ all.

Feriyanto. (2020). Tarekat Dan Moderasi Beragama (Studi terhadap Pengamalan Tanbih di Kalangan Pengamal Tarekat Qadariyah Naqsabandiyah (TQN) Pondok Pesantren Sirnarasa Ciceuri Ciamis, Jawa Barat). Tatar Pasundan: Jurnal Diklat Keagamaan, XIV(2), XIV. https://doi.org/https:/ / doi.org/10.38075/tp.v14i2.104.

Hasanah, N. (2017). Kekuatan Sastra, Literasi Media, Dan Tokoh Agama Dalam Menangkal Bahaya Radikalisme. Prosiding Seminar Nasional Program Pascasarjana Universitas PGRI Palembang, 146-150. https://jurnal.univpgripalembang.ac.id/index.php/Prosidingpps/article/view/1356.

Hidayat, Fadhil Pahlevi; Lubis, Faizal Hamzah. (2021). Literasi Media Dalam Menangkal Radikalisme Pada Siswa. Jurnal Interaksi: Jurnal Ilmu Komunikasi, 


\section{Tatar Pasundan}

Jurnal Diklat Keagamaan

PISSN 2085-4005; EISSN 2721-2866

Volume 15 Nomor 2 Tahun 2021

\section{5(2), 31-41. https:/ / doi.org/https:// doi.org/10.30596/interaksi.v5i1.5564.}

Idris, I. (2017). Membukan Deradikalisasi: Soft Approach Model Pembinaan Terorisme dari Hulu ke Hilir secara Berkesinambungan. Jakarta: Daulat Press.

Irawan, Ratna Andi; Ibda, Hamidulloh; Niam, Khoirun; Munif, Junaidi Abdul. (2019). Modul Dan Panduan Teknis Gerakan Literasi Ma'arif LP Ma'arif PWNU Jawa Tengah. Semarang: CV. Asna Pustaka.

Joyo, A. (2018). Gerakan Literasi dalam Pembelajaran Bahasa Indonesia Berbasis Kearifan Lokal Menuju Siswa Berkarakter. Jurnal Kajian Bahasa, Sastra Dan $\begin{array}{lll}\text { Pengajaran } & \text { (KIBASP), 159-170. }\end{array}$ https://doi.org/https://doi.org/10.31539/kibasp.v1i2.193.

Kanwil Kemenag Jawa Timur. (2019). Gerakan Ayo Membangun Madrasah (GERAMM). Surabaya: Kantor Wilayah Kementerian Agama Jawa Timur.

Kemdikbud. (2016). Buku Saku Gerakan Literasi Sekolah (1st ed.). Kemdikbud.

Ma'arif, Syamsul. (2020). Sekolah Harmoni: Restorasi Pendidikan Moderasi Pesantren. Semarang: CV. Pilar Nusantara.

Manshur, Fadlil Munawwar; Husni. (2020). Promoting Religious Moderation through Literary-based Learning: A Quasi-Experimental Study. International Journal of Advanced Science and Technology, 29(6), 8113-8119. http:/ / sersc.org/journals/index.php/IJAST/article/view/25252/13465.

Marzuki, K. (2019). Kasus Pengibaran Bendera HTI di SMK 2 Sragen, Ganjar: Guru dan Siswa Masih Diperiksa. Jateng.Inews.Id. https:/ /jateng.inews.id/berita/kasus-pengibaran-bendera-hti-di-smk-2sragen-ganjar-guru-dan-siswa-masih-diperiksa.

Muhtarom, M. (2018). Urgensi Penguatan Pemikiran Moderasi Islam dalam Pendidikan Agama di Madrasah. Tatar Pasundan: Jurnal Diklat Keagamaan, XII(32), 39-47. https:/ / doi.org/https://doi.org/10.38075/tp.v12i32.53.

Muliastrini, Ni Ketut Erna; Handayani, Ni Nyoman Lisna. (2021). Gerakan Literasi Digital Bermuatan Karakter Dalam Menyongsong Pendidikan Abad 21 Era Society 5.0. Prosiding Seminar Nasional Institut Agama Hindu Negeri Tampung $\begin{array}{lll}\text { Penyang Palangka Raya, } & \text { 795. }\end{array}$ https://doi.org/https://doi.org/10.33363/sn.v0i3.91.

Nugraha, Firman. (2013). Penyuluhan Agama Transformatif: Sebuah Model Dakwah. Ilmu Dakwah: Academic Journal for Homiletic Studies, 7(21).

Nugraha, Mulyawan Safwandy; Fauzan, Muhammad. (2020). Penanggulangan Potensi Radikalisme melalui Penilaian Buku Pendidikan Agama Pada Sekolah dan Madrasah. Tatar Pasundan: Jurnal Diklat Keagamaan, 14(1), 1-18. https://doi.org/https://doi.org/10.38075/tp.v14i1.47.

Saepudin, A. (2019). Islam Indonesia: Dialog Dua Kebudayaan (Studi Perbandingan Antara Budaya Islam dan Kepercayaan Kebatinan Asli Indonesia). Tatar Pasundan: Jurnal Diklat Keagamaan, https://doi.org/https://doi.org/10.38075/tp.v13i2.26.

Sailendra, H. (2020). Jateng Diindikasi Jadi Pusat Pelatihan Radikalisme. Halosemarang.Id. https://halosemarang.id/jateng-diindikasi-jadi-pusatpelatihan-radikalisme.

Sofanudin, Aji. (2017). Aktivitas Keagamaan Siswa dan Jaringan Mentoring Rohis 
SMA Negeri di Kabupaten Sukoharjo, Jurnal SMART, 3 (1).

Sofanudin, Aji. (2020, December 17). "Cegah Radikalisme di SMA. https://doi.org/10.31219/osf.io/7vx4u.

Sofanudin, Aji. "Cadar dan Ekspresi Keberagamaan". Tribun Jateng, 01/11/2017.

Sofanudin, Aji, dkk. (2020). Literasi Keagamaan dan Karakter Peserta Didik. Yogyakarta: Diva Press.

Syahputra, I. (2020). Social Media Activities and the 212 Movement: The Indonesian Ulema Council's Perspective. Al-Jami'ah Journal of Islamic Studies, 58(2), 323-354. https://doi.org/https://doi.org/10.14421/ajis.2020.582.323-354

Tim Penyusun Kementerian Agama RI. (2018). Tanyaa Jawab Moderasi Beragama. Jakarta: Badan Litbang dan Diklat Kementerian Agama RI.

Wahyu Egi Widayat, et.al. (2019). Penguatan Aswaja Annahdliyah Melalui Literasi Kampus. Semarang: CV. Pilar Nusantara.

Widodo, Priyantoro; Karnawati. (2019). Moderasi Agama dan Pemahaman Radikalisme di Indonesia. PASCA: Jurnal Teologi Dan Pendidikan Agama Kristen, 15(2), 9-14. $\quad$ https://doi.org/https://doi.org/10.46494/psc.v15i2.61. 